\title{
PROGRESS OF CHEMOTHERAPY IN LUNG CANCER
}

Oleg S. Selawry, M.D.,

Lung cancer is the most commonly lethal type of cancer in the U.S.A. 75,000 patients are expected to die this year of lung cancer in the U.S.A. This amounts to one of every five cancer deaths for both sexes or one of every three cancer deaths for males.

The five year survival remains between 8 and $10 \%$ of all patients. $50 \%$ of the patients have recognized, extrapulmonary metastases at the time of diagnosis, an additional $30 \%$ have regional disease and only $20 \%$ are surgically resectable (1). Hence, chemotherapy is potentially indicated in $50 \%$ of the patients at the time of diagnosis and in almost $90 \%$ of all patients at some time of their disease. What, then. is the current status of chemotherapy in the treatment of lung cancer, which are the limitations and where are the major gaps of knowledge?

There are published data on approximately 18,000 patients included into chemotherapeutic trials (including untreated controls) (2). For purposes of this review, we will focus on controlled and uncontrolled trials for monochemotherapy, the use of single drugs as basis for polychemotherapy and for multidisciplinary chemotherapy. For polychemotherapy and multidisciplinary treatment, we will limit the discussion to prospective, controlled clinical trials.

Where possible, data are presented by cell type, using the classification of the World

Chief, Medical Oncology Branch, Division of Cancer Treatment, National Cancer Institute, Bethesda, Maryland 20014, U.S.A.
Health Organization (3), because of the marked differences of natural history, spread of disease and response by cell type for different types of lung cancer (1-2).

It will be assumed, that the reader is familiar with basic aspects of chemotherapy. Details on drug dose, schedule and toxicity are, therefore, omitted, except for instances where drugs were used in an unusual way.

\section{Materials and Methods}

The current review is based on an ongoing literature search and on the author's own clinical experience. Only patients with microscopic confirmation of lung cancer are included. The effect of chemotherapy is measured in terms of objective tumor regression and of the time from onset of treatment to progressive disease or to death.

For purposes of this paper, objective response is defined as at least $50 \%$ regression of well-outlined pulmonary lesions or at least $25 \%$ regression of well-outlined palpable lesions, using the product of the longest $\mathrm{x}$ widest perpendicular diameters, in the absence of new lesions or of progression elsewhere. A pronounced (estimated more than $75 \%$ ) change of poorly-outlined lesions was also accepted as objective response. Not accepted are decrease of liver size and decreased serum levels of tumor-related marker substances such as human chorionic gonadotrophin, calcitonin or carcinoembryonic antigen, unless they are associated with objective tumor regression. 


\section{Objective Response to Single Drugs (Table. 1)}

The response to single drugs varies considerably depending on the microscopic type of lung cancer. It is helpful, therefore, to report responses by cell type. Lack of such reporting might obscure clinically important responses of a less common cell type in larger series of patients.

Small cell anaplastic carcinoma is definitely the most sensitive type of lung cancer: 12 drugs exerted response of $20 \%$ to $65 \%$. Complete tumor regression was reported for some of these drugs (adriamycin, BCNU, CCNU, cyclophosphamide, hexamethylmelamine, mercaptopurine and methotrexate) in a - minority of patients. This is particularly fortunate, because of the poor survival of patients with small cell carcinoma (less than $1 \% 5$ year survival of all patients, less than $5 \% 5$ year survival of resected patients (4)), because of very early spread to regional limphnodes and to distant sites.

The large cell form of anaplastic carcinoma forms a more heterogenous group including variable proportions of poorly-differentiated epidermoid and adenocarcinoma. This form of lung cancer is much less responsive than small cell carcinoma with a distinctly different spectrum of effective drugs. Procarbazine, which holds the 8 th rank of effective drugs for small cell carcinoma, has the highest reported response rate. 1-Methyl-1-nitrosourea and methotrexate, the two most active drugs for small cell carcinoma, rank as numbers 9 and 10 for large cell carcinoma.

Epidermoid - and adenocarcinoma are also less responsive than small cell carcinoma. Both show similar response to methotrexate, nitrogen mustard and cyclophosphamide, among others, but differ in their sensitivity to dibromodulcitol and to mitomycin.

These differences are not strictly quanti- tative, because of the lack of larger numbers of comparative clinical trials.

Forty-seven drugs received either no trial or insufficient exploration by cell type. Twenty-two of these drugs are new, the remaining 25 drugs lack adequate data in one or more cell types. Closure of these important gaps of knowledge would be highly desirable, with preference for drugs with novel action and/or structure and for non-myelosuppressive agents which might be uniquely suitable for combination chemotherapy, permitting the use of full dose for all drugs of a given combination.

\section{A select group of 20 of these drugs is presented in Table. 2.}

Closure of these gaps would take at least 14 patients per cell type in order to exclude a response rate of $20 \%$ with a probability of $95 \%$. If a "standard" drug, such as cyclophosphamide, was used for comparability, this number would double to 28 patients per cell type of 112 patients per unknown drug for all four cell types. This implies a backlog of almost 4,000 patients as of this time, and more patients as new drugs are developed. This task clearly requires international cooperation as it exceeds the resources of any single institution. or cooperative study group.

\section{Objective Response to Drug Combinations} (Table. 3)

The success of combination chemotherapy in tumors such as malignant lymphomas, acute leukemia of children, and in breast cancer led to a plethora of studies on combination chemotherapy for bronchogenic carcinoma.

The greatest success would be expected in small cell carcinoma, because of the large number of individually effective agents (Table. 1). Indeed, combination of two drugs is 
Table. 1 Objective response of lung cancer to single drugs by cell type (2).

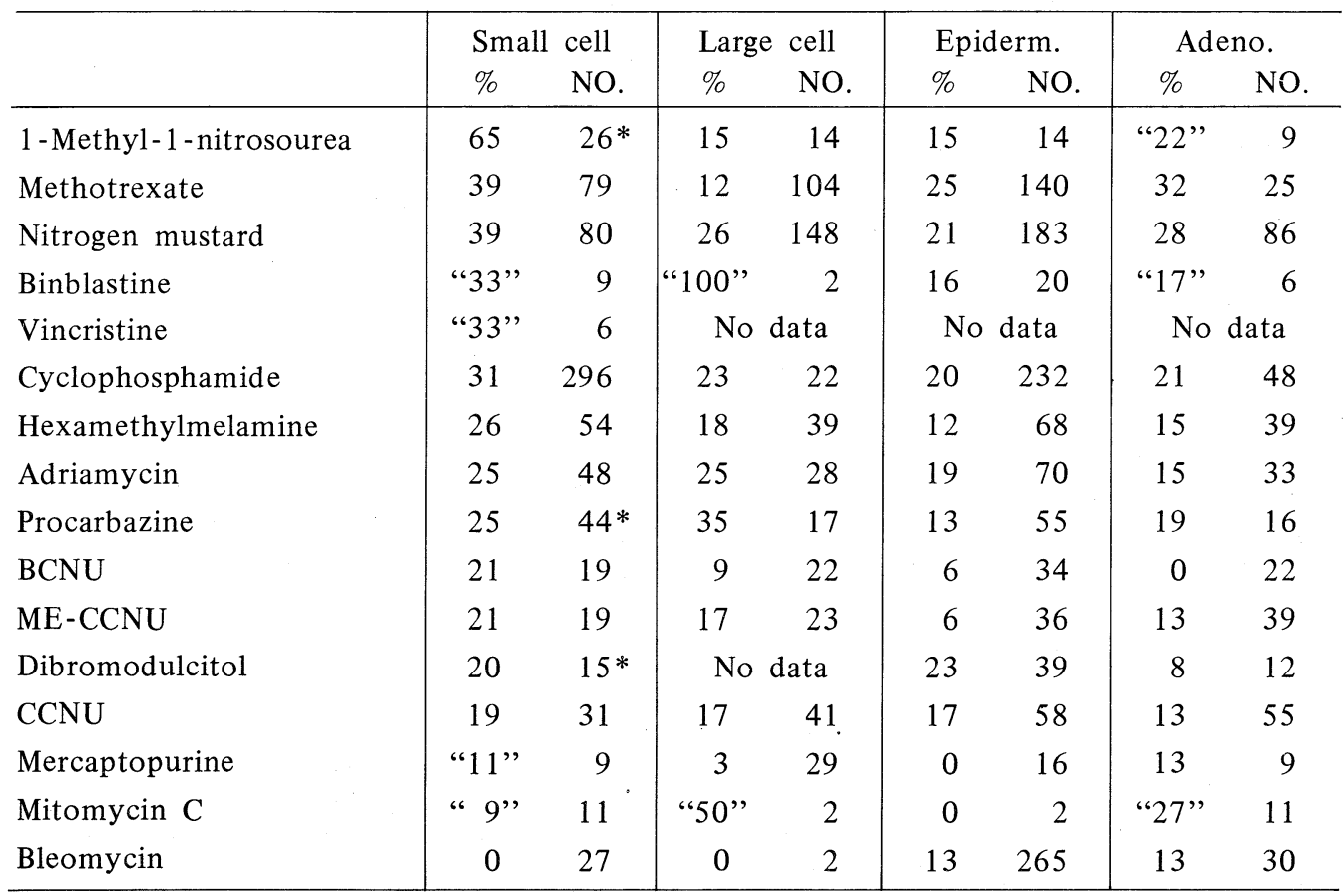

* Includes patients with large cell carcinoma.

superior to monochemotherapy, a 3-drug combination appears superior to a 2-drug combination and simultaneous use of 4-drugs is superior to sequentail use of the same four drugs (Table. 3 ).

The 3-drug combination of cyclophosphamide, methotrexate and $\mathrm{CCNU}$ appears also superior to cyclophosphamide and methotrexate for adenocarcinoma, while simultaneous use of the four drugs listed in Table. 3 is also superior for epidermoid carcinoma (increase of objective response from $14 \%$ of 22 patients for sequential use to $39 \%$ of 18 patients for simultanecus treatment).

No advantage of polychemotherapy over monochemotherapy is thus far reported for large cell carcinoma.

\section{The Relation of Tumor Regression to Survival}

In most series, patients with objective response live two to three times longer than non-responders, irrespective of cell type. This survival gain compares well or exceeds the average duration of objective response (2-3 months). Select data are summarized in Table. 4.

Critics of chemotherapy are concerned, however, with possible harm to non-responders, because their survival could be shortened by toxicity. Thus, the data in Table. 4 would be less meaningful.

The Eastern Cooperative Oncology Group addressed itself to this question in a double blinded prospective study comparing methotrexate at "high does" $(0.6 \mathrm{mg} / \mathrm{kg})$, with methotrexate at "low does" $(0.2 \mathrm{mg} / \mathrm{kg})$ with placebo, all given twice weekly i.m. for at least four months (4).

Responders lived significantly longer than 
non-responders (Table. 4). Non-responders on high and low dose methotrexate lived slightly longer (2.6 and 3 months, respectively) than non-responders on placebo (2.1 months). It was concluded, that chemotherapy with methotrexate did not shorten survival of nonresponders. This lends more credence to studies where survival is the sole criterion for "response". Indeed, such studies showed a statistically significant increase of median survival from 1.4 months (57 patients) for placebo to 4.0 months (87 patients) for cyclophosphamide in patients with small cell carcinoma and from 3 months (229 patients on placebo) to 6 months (66 patients) for patients with epidermoid carcinoma on nitrogen mustard. Interestingly, none of the other three cell types showed significant survival gain. Moreover, the study design requires many more patients than are needed for establishment of objective response: 50 patients are needed in each arm of a comparative clinical trial to determine a $50 \%$ difference in survival and 230 patients for detection of a $20 \%$ survival gain (2).

\section{Combination of Chemotherapy and Surgery}

Repeated and impressive claims have been made for superiority of surgical adjuvant chemotherapy over surgery alone on the basis of historical controls or less than strict,

Table. 2 Drugs with insufficient or no data on objective response by cell type (2).

\begin{tabular}{|c|c|c|c|c|}
\hline Drug & $\begin{array}{c}\text { Data } \\
\text { insuffic. }\end{array}$ & None & $\begin{array}{l}\text { Novel } \\
\text { struture }\end{array}$ & $\begin{array}{c}\text { Non- } \\
\text { myelosuppressive }\end{array}$ \\
\hline Acetylpicolinoylhydrazine & + & & + & \\
\hline Acronyazine & & + & + & + \\
\hline Aminochrysene & + & & + & \\
\hline Anguidine & & + & + & \\
\hline L-Asparaginase & & + & + & + \\
\hline Camptothecin & & + & + & + \\
\hline Cycloleucine & & + & + & \\
\hline Dactinomycin & + & & + & \\
\hline Diglycoaldehyde & & + & + & \\
\hline Emetine & + & & + & + \\
\hline Fluorouracil & + & & + & \\
\hline Gallium nitrate & & + & + & \\
\hline Hydroxyurea & + & & + & \\
\hline Platinum Diamminochloride & + & & + & \\
\hline Prospidine & & + & + & \\
\hline Streptonigrin & + & & + & \\
\hline Streptozotocin & & + & + & + \\
\hline Thalicarpine & & + & + & + \\
\hline Vincristine & + & & & \\
\hline
\end{tabular}

Information on source availability and tolerance of drugs produced in the U.S.A. available through Dr. M. Slavik, Cheif, Investigational Drug Branch, CTE, DCT, National Cancer Institute, Bldg. 37, Rm. 6E20, Bethesda, Maryland, U.S.A. 20014. 
prospective randomization $(5,6)$.

Eight controlled clinical trials including 5,019 patients thus far failed to confirm these data (2), using drugs such as busulfane, cyclophosphamide, nitrogen mustard and vinblastine, alone or in combination with methotrexate and/or fluorouracil. The exception to this rule might be improved survival of patients with small cell carcinoma receiving postsurgical cyclophosphamide. In some of these studies, failure might have been due to insufficient treatment (1-2 doses at or shortly after surgery in an attempt to destroy circulating tumor cells). In at least one study, there was earlier recurrence of disease, probably related to suppression of host defense mechanisms by prolonged use of cyclophosphamide. It is conceivable, however, that use of the most effective drugs or drug combinations might yet prove successful, when given in spaced treatmen ment courses, in order to permit immunologic recovery of the host. Moreover, there might be an optimal duration of treatment courses as shown for cyclophosphamide as adjuvant for radiotherapy (v.i.).

\section{Combination of Chemotherapy and}

\section{Radiotherapy}

Chemotherapy plus radiotherapy was used in 23 prospective, randomized trials, including more than 2,000 patients. Twenty studies failed to show superiority of the combined approach, either because one or both modalities of treatment were used at reduced dosage or because of inherent inefficacy. The remaining three trials indicate a statistically significant advantage for adjuvant chemotherapy (Table. $5)$. Two of these trials show a survival gain, one study shows only a difference in objective responses. The first study shown in Table. 5 is of particular methodologic interest, because four large, widely spaced doses of cyclophosphamide were as effective as 8 doses, indicating an optimal duration of treatment. Thus, exploration of the optimal duration of chemotherapy becomes a potentially important feature of adjuvant studies.

As described above, for surgery, the use of adjuvant chemotherapy might also be of disadvantage. Thus, use of either cyclophosphamide or mechlorethamine combined with methotrexate in prolonged treatment courses appeared to shorten survival of patients on adjuvant treatment.

Table. 3 Objective response to combination chemotherapy for small cell carcinoma and adenocarcinoma (2).

\begin{tabular}{lccrc}
\hline \multicolumn{1}{c}{ Drug } & \multicolumn{3}{c}{ Small cell CA } & \multicolumn{2}{c}{ Adenoca } \\
& $\%$ & NO. & \multicolumn{1}{c}{$\%$} & NO. \\
\hline Cyclophosphamide (CA) & $28^{*}$ & 88 & 15 & 26 \\
CTX + CCNU & $45^{*}$ & 83 & 5 & 21 \\
CTX + Methotrexate (MTX) & 31 & 23 & 6 & 17 \\
CTX + MTX + CCNU & 53 & 31 & 30 & 20 \\
CTX + MTX + Procarbazine & & & & \\
$\quad+$ Vincristine & $27 *$ & 11 & - & - \\
$\quad \begin{array}{l}\text { Sequentially every 2 wks } \\
\quad \text { Simultaneously }\end{array}$ & $69 *$ & 16 & - & - \\
\hline
\end{tabular}

* Difference statistically significant $(\mathrm{P}<.05)$. 
Table. 4 Relation of tumor regression to survival (2).

\begin{tabular}{|c|c|c|c|c|c|c|c|c|c|}
\hline \multirow{3}{*}{ Drug (s) } & \multicolumn{4}{|c|}{ Median survival (months) } & & & \multicolumn{3}{|c|}{ Number of patients } \\
\hline & \multicolumn{2}{|c|}{ Small cell } & \multicolumn{2}{|c|}{ Epid. } & \multicolumn{2}{|c|}{ Adeno. } & \multirow[b]{2}{*}{$\begin{array}{c}\mathrm{SM} \\
\mathrm{R}-\mathrm{N}\end{array}$} & \multirow[b]{2}{*}{$\begin{array}{l}\text { EPID } \\
\mathrm{R}-\mathrm{N}\end{array}$} & \multirow[b]{2}{*}{$\begin{array}{l}\text { ADENO } \\
\text { R-N }\end{array}$} \\
\hline & resp. & $\begin{array}{l}\text { non- } \\
\text { resp. }\end{array}$ & resp. & $\begin{array}{l}\text { non- } \\
\text { resp. }\end{array}$ & resp. & $\begin{array}{l}\text { non- } \\
\text { resp. }\end{array}$ & & & \\
\hline Bleomycin & - & - & $14+*$ & $3 *$ & $28+$ & 2 & & $31-13$ & $2-5$ \\
\hline Single Drugs** & $6.7 *$ & $2.9 *$ & $12 *$ & $6 *$ & 4.5 & $?$ & $23-57$ & $11-109$ & $1-37$ \\
\hline $\begin{array}{l}\text { Cytoxan }+ \\
\quad \text { Methotrexate }\end{array}$ & $7.3 *$ & $3.1^{*}$ & 4.5 & 1.7 & 8.6 & 4.0 & $8-15$ & $2-17$ & $1-16$ \\
\hline $\mathrm{CTX}+\mathrm{MTX}+\mathrm{CCNU}$ & 8.8 & 3.0 & 5.7 & 3.1 & 8.1 & 6.1 & $18-13$ & $2-15$ & $6-14$ \\
\hline & \multicolumn{4}{|c|}{ All Cell types } & \multirow{2}{*}{\multicolumn{2}{|c|}{$2.3^{*}$}} & \multicolumn{3}{|c|}{ All Cell Types } \\
\hline $\begin{array}{l}\text { CCNU or Methyl- } \\
\text { CCNU }\end{array}$ & \multicolumn{3}{|c|}{$12.6^{*}$} & & & & \multicolumn{3}{|c|}{$6-79$} \\
\hline Hexamethylmelamine & \multicolumn{3}{|c|}{$8.4 *$} & & \multicolumn{2}{|l|}{$2.6^{*}$} & \multicolumn{3}{|c|}{$14-41$} \\
\hline Nitrogen Mustard & \multicolumn{3}{|c|}{7} & & \multicolumn{2}{|l|}{3.5} & \multicolumn{3}{|c|}{$8-13$} \\
\hline Methotrexate (4) & \multicolumn{3}{|c|}{$7.9 *$} & & \multicolumn{2}{|l|}{$2.6^{*}$} & \multicolumn{3}{|c|}{$14-71$} \\
\hline
\end{tabular}

* Difference significant $(\mathrm{P}<.05)$

** Single agents include antibiotics, antimetabolites, cyclophosphamide, ethylenimines, nitrogen mustard, 1-methyl-1-nitrosourea and sarcolysine.

Table. 5 Chemotherapy as adjuvant to radiotherapy.

Three Controlled Trials with Statistically Significant Differences (2).

\begin{tabular}{|c|c|c|}
\hline Treatment & Survival (months) & Number of Patients \\
\hline $4,000-5,000 \mathrm{R}$ in $4-5 \mathrm{wks}$ & 7.2 median & 42 \\
\hline $\begin{array}{l}\text { Same as above plus cyclo- } \\
\text { phosphamide } 1000 \mathrm{mg} / \mathrm{M}^{2} \\
\text { q. } 3 \text { wks for } 4 \text { or } 8 \text { doses }\end{array}$ & 10.2 median & $\begin{array}{ll}38 & (4 \text { doses }) \\
35 & (8 \text { doses })\end{array}$ \\
\hline $5,000 \mathrm{R}$ in $5 \mathrm{wks}$ & 4.9 mean & 15 \\
\hline $\begin{array}{l}\text { Same as above plus chlor- } \\
\text { ambucil to WBC } 2-4000 / \mathrm{mm}^{3} \\
2-8 \mathrm{mg} / \text { day }\end{array}$ & 7.6 mean & 15 \\
\hline $6,000 \mathrm{R}$ in $6 \mathrm{wks}$ & $31 \%$ one year* & 48 \\
\hline $\begin{array}{l}\text { Same as above plus cyclo- } \\
\text { phosphamide } 200 \mathrm{mg} / \mathrm{d} \times \\
5 \text { per wk }\end{array}$ & $35 \%$ one year* & 46 \\
\hline
\end{tabular}

* No difference in survival. Statistically significant difference of objective response, when evaluation is based on both, chest film and endobronchial observation. 


\section{Summary and Prospects}

Monochemotherapy is of established value for palliative treatment of patients with lung cancer. The choice of drug depends greatly on the cell type of bronchogenic carcinoma. The response also depends on effective use of chemotherapy to a level of definite, safely reversible toxicity. Symptomatic improvement and prolongation of survival can be expected in approximately $20-60 \%$ of the patients, depending on cell type, performance status, possibly immunologic status and extent of disease.

Further improvement is well within reach, as more currently available drugs are tested.

Combination chemotherapy is particularly superior to monochemotherapy for the treatment of small cell carcinoma, as the most sensitive cell type. Development of mutually non-crossresistant, highly effective drug combinations for sequential use might lead to further increase of survival, possibly approaching "cure" with currently available drugs.

These chances might be further augmented by combination of chemotherapy with radiotherapy to the bulk of the tumor mass, with reductive surgery or with both.

Combination of chemotherapy with radiotherapy proved successful with proper selection of agents and with both treatment modalities given to full dose.

Combination of chemotherapy and surgery remains experimental at the present time, with promise based on judicious choice and timing of drugs.

Combination of chemotherapy and nonspecific or specific immunostimulation is under investigation at several major centers, with apparent promise. An appraisal of these deta will have to await more detailed presentation and evaluation.

The excellent help of a team of coworkers, foremost, Dr. Lawrence Broder, Ms. Tamara Voss, Ms. Elise Mackie, Ms. Bernice Brown, and Ms. Annette Klanchar, is gratefully acknowledges.

Many of the thoughts and concepts evolved in discussions with my immediate co-workers, my colleagues at the Working Party for Therapy of Lung Cancer, and with other foremost investigators in the field, and are, therefore, in no way original.

\section{REFERENCES}

1. Selawry, O.S. and Hansen, H.H.: Lung cancer, in Holland, J.F. and Frei, E.T.(eds) Cancer Medicine. Philadelphia, Lea \& Febiger, 1973, pp. 1473-1518.

2. Selawry, O.S.: On chemotherapy of lung cancer, in Israel, L. (ed) Lung Cancer, Facts, Concepts and Strategies. New York, Basel, S. Karger, in press.

3. Kreyberg, L.: histologic typing of lung tumors, Geneva, World Health Organization, 1967.

4. Selawry, O.S., Krant, M., Scotto, J., et al: Methotrexate compared with placebo in lung cancer. Amer. Rev. Resp. Dis., in press.

5. Karrer, K., Pridun, N. and Zwintz, E.: Chemotherapeutic studies in bronchogenic carcinoma by the Austrian study group. Cancer Chemother. Rep., Part 3, 4:207-214 1973.

6. Pavlov, A., Pirogov, A., Trachtenberg, M., et al: Results of combination treatment of lung cancer patients: surgery plus radiotherapy and surgery plus chemotherapy. Cancer Chemother. Rep., Part 3, 4:133-136, 1973. 